\title{
Henri Wallon en castellano: jalones argentinos de un itinerario transnacional (1935-1976)*
}

\author{
Henri Wallon in Spanish: Argentine Milestones \\ of a Transnational Itinerary (1935-1976)
}

Recibido: noviembre 14 de 2013 | Revisado: julio 26 de 2014 | Aceptado: julio 27 de 2014

\author{
LuCIANO NiCOLÁs GARCía** \\ Universidad de Buenos Aires, Argentina
}

Para citar este artículo: García, L. N. (2014). Henri Wallon en castellano: jalones argentinos de un itinerario transnacional (1935-1976). Universitas Psychologica, 13(5), 1835-1845. http://dx.doi. org/10.11144/Javeriana.upsy13-5.hwcj

Artículo de investigación. Agradecimientos: Este artículo se realizó en el marco del proyecto UBACyT 2002010010062-01/W627, julio 2011 - junio 2014, "Conocimientos, prácticas y valores en la historia de la psicología y del psicoanálisis en la Argentina", dirigido por la Dra. Florencia Adriana Macchioli, Programa de Estudios Históricos de la Psicología en la Argentina, Instituto de Investigaciones, Facultad de Psicología, UBA. La investigación fue financiada mediante una beca posdoctoral otorgada por el Consejo Nacional de Investigaciones Científicas y Técnicas. Agradezco a Leandro Carbón y Ana Belén Amil, por sus comentarios y correcciones a versiones previas de este artículo.

** Facultad de Psicología, Universidad de Buenos Aires. Consejo Nacional de Investigaciones Científicas y Técnicas. Dirección postal: José de Amenabar 3140, piso 8.o, departamento 'C' (C1429AEF), Ciudad Autónoma de Buenos Aires. Teléfonos: + $54+113529$ 7217; + 54 + 9116795 0989. Correo electrónico: lngarcia@psi.uba.ar

\section{RES U MEN}

Este artículo indaga las lecturas y traducciones al castellano de la obra de Henri Wallon en la Argentina, desde la perspectiva de la historia transnacional. Se reconstruye la trayectoria política de Wallon en Francia y la conformación de un circuito intelectual y científico antifascista, filosoviético y comunista que propició la circulación y edición de sus obras. Se analiza la caracterización de la figura de Wallon y el uso de sus ideas por intelectuales antifascistas, pedagogos cercanos al comunismo y psiquiatras de izquierda críticos del comunismo. Finalmente, se realizan algunas indicaciones historiográficas en pos de una historia de la psicología en América Latina, desde el marco de la historia transnacional.

Palabras clave

historia transnacional; psicología del desarrollo; antifascismo; comunismo

\section{A B S T R A C T}

This article examines readings and translations to Spanish of the work of Henri Wallon in Argentine from the perspective of Transnational History. The political trajectory of Wallon in France is reconstructed as well as the constitution of an intellectual and scientific circuit in anti-fascism, philoSovietism, and communism that promoted the circulation and edition of his work. Wallon's characterization and use of his ideas by antifascist intellectuals, pedagogues close to communism and leftist psychiatrist critical of communism is analyzed. Finally, some remarks on historiographical issues are made so as to propose a transnational history of psychology in Latin America. Keywords

Transnational history; developmental psychology; antifascism; communism 


\section{Introducción}

El análisis de la circulación de los saberes requiere considerar los procesos de traducción idiomática de los mismos. Si bien los especialistas suelen apropiarse de saberes en sus idiomas de origen, es evidente que las traducciones extienden los procesos de recepción, al ampliar el público lector. Ello es especialmente destacable en un espacio como el de América Latina, donde diversos países comparten una misma lengua y por tanto el público potencial es vasto. Aunque este punto es relevante en las dinámicas de la difusión y apropiación internacional de un autor (Vezzetti, 1991), la aparición de traducciones de obras foráneas requiere de un marco de análisis más amplio para dar cuenta de un modo acabado de los procesos de lectura y acreditación de un saber. Se hace necesario atender las condiciones que dieron relevancia a cierto saber u obra y los mecanismos que hicieron de una traducción una empresa viable. Si bien las traducciones son solo un eslabón de diversos procesos de recepción, analíticamente pueden ser un punto de partida para reconstruir redes intelectuales, políticas y científicas, y sopesar la incidencia de ciertos saberes en un contexto particular.

En esta perspectiva, este artículo se detiene en las traducciones de la obra Henri Wallon (1879. 1962), para analizar la circulación de saberes psicológicos a partir de una trama de discusiones intelectuales y coyunturas políticas que fueron constitutivas de la difusión y legitimación de dicha obra. Este texto busca mostrar que el modo en que dicha obra fue leída y traducida requiere contemplar el rol que el autor tuvo dentro de la política y la cultura de izquierda. Se adopta para ello la perspectiva de la historia transnacional, para analizar los circuitos intelectuales e institucionales que promovieron la introducción y traducción de las obras de Wallon al mundo de habla castellana. La historia transnacional se propone "el estudio de movimientos y fuerzas que trascienden los límites nacionales" (Iriye, 2004, p. 213), esto es, ideas, colectivos o instituciones que se organizan con cierta autonomía de las fronteras políticas y aparatos de gobierno de los Estados nación, en pos de intercambios y transacciones intersocietales. La transnacionalidad de la ciencia en el siglo XX tuvo diversos soportes: relaciones de instituciones científicas y académicas, no necesariamente universitarias o estatales; la movilidad de científicos e intelectuales, que permitió la circulación de ideas, modos de trabajo y pautas de sociabilidad; la circulación de productos científicos, como literatura, tecnología, test, procedimientos metodológicos, técnicas administrativas, entre otros y las políticas de intercambio científico promovido por instituciones no científicas ni académicas, lo que incluye a los Estados nación, pero no se limita a ellos (Heilbron, Guilhot, \& Jeanpierre, 2008).

Este último punto requiere cierto detalle. En primer lugar, la perspectiva transnacional pretende desligarse del presupuesto del Estado nación como marco de inteligibilidad de los procesos. Comúnmente, las historias críticas de la psicología, contra la idea de una universalidad ahistórica de la ciencia, han puesto de relieve las particularidades nacionales que modulan la producción de saberes (p. ej., Carroy, Ohayon, \& Plas, 2006; Hermann, 1996; Massimi \& Carmo Guedes, 2004; Vezzetti, 1996). Este enfoque, cuyos réditos son innegables, no agota el análisis de los procesos que permitieron y encauzaron la circulación de saberes. El enfoque transnacional no busca socavar la importancia de los Estados nación, sino descentrarlos del análisis a fin de incorporar otras instancias involucradas en la circulación de conocimientos y prácticas (Turchetti, Herran, \& Boudia, 2012). De lo que se trata es de adoptar una perspectiva desplazada de la universalidad o la nacionalidad, y centrada en la tensión entre particularidades locales y organizaciones con despliegue internacional. Aquí interesa tematizar a los partidos comunistas occidentales -en este caso el francés y el argentino- como parte de una red de organizaciones transnacionales que actuaban de modo coordinado en diversos países (Prado Acosta, 2013). Parte de su tarea consistió en la cooptación y formación de intelectuales para producir y difundir saberes compatibles con la ideología comunista. En ello, promovieron la circulación de saberes científicos diversos, de los que aquí interesan los psicológicos y psiquiátricos. En este punto, los partidos comunistas buscaron insertarse y disputar campos 
académicos y profesionales con saberes específicos, sin por ello perder perspectivas políticas. Como se buscará mostrar aquí, los avatares políticos del comunismo fueron un componente fundamental en la construcción de los circuitos que permitieron la circulación castellana de la obra de Wallon. En este sentido, este artículo no se centra en las tesis de Wallon, comentadas por una vasta literatura, sino que indica los medios que permitieron la introducción de sus ideas en la Argentina, en pos de reubicar al psicólogo francés y su obra dentro de la psicología hispanoparlante y de la intelectualidad comunista.

\section{Wallon, antifascismo y filosovietismo: Aníbal Ponce y Emilio Troise}

Proveniente de una familia republicana y dreyfusarde, luego de la Primera Guerra Mundial, Wallon se alineó con los sectores de izquierda que adherían al bolchevismo ruso. A mediados de la década de 1920, dirigió sus intereses hacia las aplicaciones de la psicología. En 1925, fundó el laboratorio de psicobiología del infante, orientado a tópicos pedagógicos, y anexado en 1927 a l'École Practique des Hautes Études, cuando devino presidente de la misma. Dos años más tarde, junto a Henri Piéron, Henri Laugier y Jean-Maurice Lahy, fundó el Instituto de Psicología y el Instituto Nacional Orientación Profesional (Le Bianic, 2005). Los cuatro mencionados asistieron en 1931 a la VII Conferencia de Psicotécnica, realizada en Moscú, en pleno momento de la "revolución cultural" iniciada por Stalin. A su retorno, fueron convocados a dar su impresiones sobre el evento al Cercle de la Russie Neuve (CRN), una organización impulsada por la Sociedad Panrusa para las Relaciones Culturales con el Extranjero (VOKS), institución de propaganda creada para cambiar la percepción que los intelectuales, científicos y artistas occidentales tenían de la URSS (Stern, 2007). Durante la exposición, surgió el problemático tema de las relaciones entre ciencia y política; Pierón y Laugier rechazaron la vinculación entre ambas esferas, Lahy y Wallon creyeron necesaria y productiva esa vinculación. La invitación del CRN resultó un hito en el recorrido de Wallon y para 1932 presidía su comisión científica, que reunía figuras como el físico Paul Langevin, el biólogo Marcel Prenant, el sociólogo Georges Friedmann y el filósofo Georges Politzer, todos ellos fuertemente alineados al Partido Comunista Francés (PCF) y al marxismo-leninismo soviético (Gouarné, 2010). Esta comisión significó el inicio de un esfuerzo sostenido dentro del espacio comunista y filosoviético, por transformar el estatus epistémico y político de las ciencias humanas y naturales, mediante el materialismo histórico y dialéctico soviético, propuesto como un criterio científico superador y orientado a la construcción del socialismo.

La actividad de sectores profascistas en Francia llevó a la creación del Comité de Vigilance des Intellectuels Antifascistes (CVIA), liderado entre otros por Langevin, y del cual Wallon y varios de los miembros del CRN participaron. El movimiento de intelectuales antifascistas se articuló rápidamente con las políticas de la URSS, que en 1935, mediante la Internacional Comunista, propuso el abandono de la estrategia de "lucha de clase contra clase" y adoptó la de los "frentes populares", para oponerse al auge de los fascismos. Los científicos e intelectuales dejaron entonces de ser caracterizados como elementos burgueses y fueron integrados en la movilización antifascista, la cual rápidamente se transformó en un movimiento internacional, con una importante raigambre en América Latina (Celentano, 2006). Con el avance de los fascismos, Wallon adhirió definitivamente al ideario comunista; en su artículo de 1936 "Espíritu crítico y agnosticismo" afirmó: "[El] encuadre del pensamiento humano en la evolución universal de las cosas y su acción para reconocerlo es lo que Marx y Engels han denominado materialismo dialéctico (...). Progreso del conocimiento científico y del espíritu crítico se confunden allî" (1965, p. 73).

En la Argentina, Aníbal Ponce y Emilio Troise reivindicaron las ideas políticas y científicas del psicólogo francés en los años de entreguerras. El primero dedicó buena parte de su trabajo intelectual y docente a la psicología, a partir una formación médica incompleta y una formación filosófica signada por su principal mentor, José Ingenieros. Ponce conoció a Wallon en 1929, en el laboratorio del 
Collège de France cuando visitó a Henri Pierón. A partir de entonces, comenzó a impartir los trabajos del francés en sus clases de psicología en el Instituto Nacional del Profesorado Secundario (INPS) y a citarlos en sus textos de psicología, como Problemas de psicología infantil y Ambición y angustia de los adolescentes, ambos publicaciones de cursos brindados en el Colegio Libre de Estudios Superiores (CLES) en 1930 y 1931, respectivamente.

Hacia 1933, Ponce adoptó una postura decididamente filosoviética, la cual se vio reforzada con su compromiso con el CVIA y el antifascismo europeos. Estos sirvieron de modelo para la organización en la Argentina de la Asociación de Intelectuales, Artistas, Periodistas y Escritores (AIAPE) y el CLES (Pasolini, 2008). Ambas organizaciones, que reunieron a un sector considerable de los intelectuales liberales y de izquierda, organizaron actividades culturales para defender las libertades civiles y denunciar los movimientos fascistas locales y extranjeros. En 1935, Ponce viajó a Francia, Rusia y España y se puso en contacto con intelectuales antifascistas, filosoviéticos y comunistas, entre ellos Wallon y los miembros de CRN. Mientras que antes consideraba al francés como un correcto investigador, esta vez Ponce apreció su compromiso con la causa republicana en España. Wallon, según Ponce, denunciaba que la beligerancia de la burguesía y el fascismo atacaban el trabajo intelectual y científico. Así, el francés encarnaba para Ponce el modelo de científico comprometido con la liberación y el avance cultural de los pueblos: "Hasta ayer no era más que un sabio. Hoy es un hombre completo" (1935/1974, p. 108). Acorde a las ideas de los científicos del CRN, como Wallon, Prenant o Friedmann, Ponce promovió a partir de entonces la vinculación de las ciencias con el marco epistemológico y político del marxismo-leninismo, tanto en sus libros y cursos psicológicos y políticos, como desde la revista Dialéctica, la última iniciativa intelectual de envergadura antes de su repentino fallecimiento.

Por su parte, Emilio Troise, un médico socialista filocomunista, fundador de la AIAPE y presidente de la misma, luego del fallecimiento de Ponce, también recurrió a Wallon y los miembros del CRN en su libro Materialismo dialéctico. Wallon era citado desde los volúmenes de À la lumière du marxisme, que reunían escritos de los científicos e intelectuales del CRN, para sostener, contra el idealismo que detentarían Henri Bergson y Benedetto Croce, que "La ley y la causa no están en el comienzo mismos de nuestro conocimiento de lo real. Nacen en el proceso de ese conocimiento, cuando hemos observado, confrontado, interrogado algo en la naturaleza o en nosotros" (Troise, 1938, pp. 119-120). El libro, cuyas sucesivas ediciones formaron durante décadas a los comunistas argentinos, proponía una cosmovisión científica del hombre, la historia y la naturaleza desde las ideas de Wallon, Prenant, Engels, Lenin, Pavlov, Labriola y Plejanov.

Estas apropiaciones dentro del circuito antifascista local definieron el tono en el cual la psicología del francés fue considerada posteriormente, aunque las traducciones argentinas de sus publicaciones tuvieron que esperar hasta la finalización de la guerra.

\section{Primeras traducciones y usos de Wallon: Antonio Merani y Berta Braslavsky}

Luego del inicio de la Segunda Guerra Mundial, Wallon y los miembros del CRN se unieron a la resistencia contra la ocupación nazi. Esa experiencia lo acercó aún más al PCF, al cual se afilió en 1942. Inició así una carrera política, primero como secretario de educación nacional en 1944, y más tarde como diputado durante el bienio de 1945-1946, cuando redactó el célebre informe Langevin-Wallon sobre el sistema educativo. Devino director de La Pensée en 1944, fundó la revista Enfance en 1948 y dirigió La Raison desde 1951, publicaciones en las que buscó desarrollar el proyecto científico-político iniciado en el CRN y se mostró como un militante convencido del PCF. En estos años, el PCF ganó un gran prestigio político e intelectual, dentro y fuera de Francia, por su rol en la resistencia contra la ocupación nazi (Judt, 1994), prestigio que Wallon encarnó para los psiquiatras y pedagogos argentinos.

Las traducciones argentinas de la obra walloniana se iniciaron en 1946 con Psicología aplicada, realizada por la editorial Futuro, dirigida por el intelectual comunista Raúl Larra. El prólogo de la edición remarcó la caracterización que Ponce 
hizo de Wallon, así como la afiliación del psicólogo francés al PCF, junto con Languevin, Prenant y otros. Además, se indicó que el libro "es sobre todo, una agudísma crítica [...] de los errores, de la disimulada persistencia de criterios metafísicos de muchos psicólogos contemporáneos, y del fácil peligro que ofrece una aplicación mecánica de los métodos experimentales"; se advertía del mal uso de los test en las escuelas y por tanto se consideraba que "esta obra puede ser singularmente provechosa para los maestros" (Martínez, 1946, pp. 9-10). Al año siguiente, la editorial Lautaro, organizada por el PCA, editó una de las obras mayores de Wallon, Del acto al pensamiento. El prologuista destacó "la orientación decidida y consecuentemente cientificista" del francés contra las herencias positivistas y el bergsonismo y lo ubicó como un "sabio beligerante en la gran contienda social y doctrinaria de nuestro siglo" (Weinberg, 1947, pp. 7-8). Se puede ver que Wallon era un autor marcado por el ideario comunista, entre cuyos impulsores se cuentan a Ponce y Troise.

Por otro lado, en 1948 la editorial Kapelusz, sin relación con el PCA y orientada al campo pedagógico, comenzó a editar el Nuevo tratado de psicología de Georges Dumas, que contenía dos capítulos a cargo de Wallon. Además de estas traducciones, cabe destacar dos figuras que se formaron con Wallon en el laboratorio de psicobiología del infante, Antonio Merani y Berta Perelstein de Braslavsky. Merani se doctoró en 1943 en filosofía y ciencias de la educación en la Universidad Nacional de La Plata y luego de la Segunda Guerra Mundial trabajó y mantuvo contacto regular con el psicólogo francés, hasta el fallecimiento de este. Aunque Merani no estaba afiliado al PCA, su evidente entusiasmo por las tesis de Wallon y Pavlov, sus citas a Marx, Ponce y Lysenko, y su rechazo al psicoanálisis permiten ubicarlo dentro de la cultura comunista. A partir de la noción de aprendizaje, Merani ofrecía una perspectiva que articulaba una idea de desarrollo walloniana, con una noción de ambiente basada en los mecanismos de condicionamiento y una interpretación marxista del ambiente social del niño. Por ejemplo, afirmaba: "todo estado de conciencia debe traducirse como 'actividad práctica', esto es la comprobación por la acción de las leyes reflejadas en la conciencia (Pavlov, Wallon [...])" (1957, p. 90, cursivas del autor). Durante los años cincuenta, Merani publicó varios libros donde expandió esta perspectiva, antes de emigrar de la Argentina con el cambio de década.

Por otro lado, Braslavsky, una militante de la juventud comunista, se formó en psicología con Ponce en el INPS y en 1948 se formó durante cuatro meses con Wallon, René Zazzo y Henri Prudhommeau en patologías relacionadas con el aprendizaje, como la dislexia y modalidades de evaluación clínica y uso de test. El conocimiento que allí adquirió fue aplicado en el Instituto Argentino de Rehabilitación, fundado dos años antes con el apoyo del psiquiatra pavloviano del PCA Julio Peluffo (Braslavsky, 1996). Los resultados de esa aplicación se comentaron en el libro La querella de los métodos de enseñanza de la lectura, de 1962, donde Braslavsky revisaba los métodos pedagógicos de lectoescritura predominantes y adoptaba una concepción del desarrollo basada en la articulación de las ideas de Wallon, Piaget, Leontiev y Pavlov (1962/1992).

La articulación entre las ideas de Wallon y Pavlov reviste una doble importancia: primero, estaba habilitada por el mismo Wallon quien, acorde a la política científica de la URSS, buscó modos de articular su psicología con la neurofisiología; segundo, fueron los psiquiatras del PCA quienes promovieron nuevas traducciones de Wallon en los sesenta, aunque, como se mostrará, en una clave conflictiva.

\section{Wallon en las disputas por una psicología marxista: José Itzigsohn y Antonio Caparrós}

Hacia principios los cincuenta, se conformó dentro del PCA un círculo de psiquiatras que buscó estructurar una corriente pavloviana, en consonancia con la entronización de Pavlov en la URSS y el rechazo del psicoanálisis por parte del comunismo occidental. Ese círculo fue liderado por Jorge Thénon y Peluffo, quienes fueron figuras importantes en la AIAPE y el CLES. Thénon organizó un seminario privado de formación en teorías pavlovianas, al que asistieron regularmente los psiquiatras José Itzigso- 
hn y Antonio Caparrós. Estos últimos, a principios de la década de 1960, lograron insertarse en la reciente carrera de psicología de la Universidad de Buenos Aires (UBA), donde comenzaron a desarrollar posturas teóricas heterodoxas que resultaron en fricciones dentro del mencionado círculo pavloviano. Para entonces, el PCA se encontraba muy debilitado en el plano político e intelectual argentino (Tortti, 2002) y el pavlovismo languidecía frente a la notable incidencia del psicoanálisis en la psicología y psiquiatría. Dentro de esa situación, Itzigsohn, quien en 1964 llegó a ser director de la mencionada carrera, y Caparrós buscaron diversas referencias alternativas al pavlovismo y el psicoanálisis para ofrecerlas a los estudiantes. Entre esas referencias, dieron especial importancia a Wallon. Ambos compartían el creciente malestar de los intelectuales comunistas con la línea partidaria. Caparrós se vinculó a grupos expulsados del PCA como el de la revista La rosa blindada y Vanguardia revolucionaria, por lo que se distanció del círculo pavloviano, férreo defensor del PCA. Itzigsohn también cuestionó el dogmatismo de sus camaradas y, como miembro activo de la comunidad judía, resintió la posición comunista frente al problema del antisemitismo soviético y el conflicto de Oriente Medio. Además, se mostraban molestos por el escaso interés de sus camaradas en sus actividades dentro de la populosa carrera de psicología (García, 2012).

En ese contexto, Itzigsohn y Caparrós actuaron como asesores de las editoriales Lautaro y Proteo, vinculadas al PCA, que en 1964 y 1965 realizaron sucesivas traducciones de artículos y libros de Wallon. De esa tarea editorial, cabe destacar el prólogo que Caparrós escribió para la nueva edición de Del acto al pensamiento. Allí remarcó la adscripción político-epistémica del francés: "Toda su obra psicológica es una expresión del materialismo dialéctico [...] cuya interioridad conceptual es, metodológica y conceptualmente, sencillamente marxista" (Caparrós, 1964, p. 7). En ese libro, se exponían las principales tesis wallonianas sobre el rol central de las emociones en el desarrollo cognitivo y social de los niños. En su lectura, Caparrós destacó que la indiferenciación yo/otro postulada por Wallon revelaría que el proceso de individuación infantil es resultado de su socialización. Para Caparrós, esta tesis tiene valor no solo psicológico, sino también "doctrinario": "el hombre se individualiza más profundamente en tanto se socializa más profundamente. Tal cual Marx formulara, Wallon demuestra que el hombre es el conjunto de sus relaciones sociales" (pp. 18-19, cursivas del autor).

Acreditado Wallon como un genuino marxista, Caparrós cuestionó al psicoanálisis y al pavlovismo. Por un lado, apoyado en las ideas de Wallon sobre el sincretismo, cuestionó al psicoanálisis anglosajón, entonces predominante entre los psicoanalistas argentinos, refiriéndose a las teorías de Melanie Klein como "puro fuego de artificio mental", dado que consideraba "indemostradas [las] fantasías inconscientes en el niño” (p. 19). Cuestionó además el modo en que Freud pensaba la relación psiquis/ soma: "lo biológico fue en él pura metafísica, o si se quiere, mera explicación pragmático-fantasmagórica, que llenaba un hueco que necesitaba cubrir en su teoría". Wallon, por el contrario, daba cuenta de "la evolución genética, dialécticamente captada, de la realidad de los procesos que marcan la continuidad y discontinuidad simultáneas de lo fisiológico y lo psicológico" (p. 12). Desde su perspectiva, la insistencia de Wallon en los aspectos biológicos del desarrollo resultaba de un esfuerzo por captar la unidad del hombre, cosa que el psicoanálisis, al dejar de lado dichos aspectos, no podría hacer.

Por otro lado, Caparrós cuestionó la teoría pavloviana al señalar en Konstantin Bikov, uno de los discípulos de Pavlov más reputado en la Argentina, una tendencia al reduccionismo fisiológico similar al de la psicología positivista decimonónica, indicación que era simultáneamente una crítica epistémica y política. Caparrós encontraba al pavlovismo local estrecho y poco informado: "Demasiado preocupados por oponer a las corrientes psicoanalíticas una fundamentación científico-natural de los fenómenos psicológicos, los psiquiatras marxistas han dejado de lado casi por completo la producción de los psicólogos marxistas"; aún más, el dogmatismo de sus camaradas "ha dificultado el desarrollo de una teoría y una práctica psicológica con un enfoque marxista" (p. 23). En rigor de verdad, ni Itzigsohn ni Caparrós rechazaron de plano la neuro- 
fisiología pavloviana. Sin embargo, el objetivo para Caparrós e Itzigsohn era destacar la especificidad de la psicología y evitar reducciones varias, perspectiva que Wallon defendió enfáticamente en su artículo de 1956 "Sobre la especificidad de la psicología":

La psicología no es la pedagogía, ni la moral, ni la política, ni la técnica de los oficios, ni la organización del trabajo, ni la medicina o la fisiología [...]. Su individualidad, su unidad, su especificidad consiste en estudiar al hombre en relación con los medios en que debe actuar, con las actividades a las que se entregue. Es a ella a quien corresponde mostrar al hombre en el animal y que el hombre ya no es animal. (Wallon, 1965, pp. 40-41)

Así, la teoría genética de Wallon era presentada a la creciente comunidad de psicólogos como específicamente psicológica y alternativa a la disyuntiva psicoanálisis/pavlovismo.

La introducción de Wallon permitía además disputar a pavlovianos y psicoanalistas de izquierda la fundamentación de una psicología marxista, como queda revelado en el debate que Caparrós sostuvo con José Bleger en una mesa redonda realizada en julio de 1965 en la Facultad de Filosofía y Letras de la UBA. Para entonces, Bleger, psicoanalista de la Asociación Psicoanalítica Argentina y ex-afiliado del PCA, ya era una referencia central para el alumnado de psicología, entre otras cosas por proponer una interpretación marxista del psicoanálisis a partir de la obra temprana de Politzer, autor del que editó unas Obras completas en 1965 y 1966 (Dagfal, 2009). En esa mesa, Bleger distinguió la obra de Politzer en dos momentos, la previa a su afiliación al PCF, la cual reivindicaba como un genuino aporte a la psicología, y la posterior a su ingreso a las filas comunistas, cuando consideraba que Politzer había reducido la psicología a un "economicismo grosero" que lo llevó a "automutilarse" al subordinar el conocimiento a la acción política (Bleger, Caparrós, Pichon-Rivière, \& Rozitchner, 1969). De este modo, frente a una creciente politización hacia la izquierda de los estudiantes universitarios (Buchbinder, 2005), Bleger defendió la autonomía científica y profesional de la psicología. En este punto, recurrió a la figura de Wallon, cuya obra conocía y citaba regularmente en sus textos: "Wallon supo tener su posición ideológica, pero nunca se dejó atropellar, jamás se dejó anular como psicólogo" (Bleger et al., p. 21). Caparrós rechazó la postura de Bleger y consideró que toda profesión o saber, si quiere ser un elemento de liberación social, debe involucrarse políticamente. Contra la interpretación de Bleger, para Caparrós Wallon ejemplificaba la fuerte articulación entre militancia política e investigación psicológica:

[Wallon] se incorporó sin vacilar a las fuerzas de la resistencia [...] y luchó por la misma causa por la que fue fusilado Politzer. [...] [N]o se oponen ni se excluyen la actividad militante y la científica; pero si en un momento se excluyeran, la militante es la actividad del hombre, la científica la del especialista; es preciso elegir entre la actividad militante que nos une al todo social o la científica que nos diferencia del mismo [...]. (pp. 36-37, énfasis del autor)

De este modo, resultaba inadmisible una psicología que no se articulase con una perspectiva política. Caparrós se encontraba entonces en un momento de paso entre la política partidaria y alternativas radicalizadas a la misma. Pocos meses después su posición se resolvió cuando Ernesto "Che" Guevara lo convocó para la organización del Ejército de Liberación Nacional en la Argentina (Vezzetti, 2009). Modelo para ambas posturas, las del experto y la del luchador político, la introducción de Wallon en esos años estuvo cruzada por discusiones políticas mayores que justificaban una orientación marxista de la psicología.

Considerado lo trabajado hasta aquí, y como se observa fácilmente en la Tabla 1, las traducciones de la obra de Wallon coincidieron con dos momentos particulares del comunismo argentino e internacional. Un primer momento, luego de la Segunda Guerra Mundial, cuando la intelectualidad comunista francesa logró una gran reputación y los intelectuales y pedagogos formados en el clima del antifascismo y el comunismo promovieron las ideas del francés. Y en un segundo momento, de crisis local e internacional del comunismo, cuan- 
TABLA 1

Textos de Wallon editados en Argentina entre 1946 y 1968

\begin{tabular}{|c|c|c|c|}
\hline Autor/es & Título & Año* & Editorial \\
\hline H. Wallon & Psicología aplicada & $1946[1938]$ & Futuro \\
\hline H. Wallon & Del acto al pensamiento (1a. ed.) & $1947[1942]$ & Lautaro \\
\hline H. Wallon & $\begin{array}{l}\text { El problema biológico de la conciencia. En G. Dumas } \\
\text { (Ed.), Nuevo tratado de Psicología (Vol. 1, pp. 351- } \\
\text { 397). }\end{array}$ & 1948 [1930] & Kapelusz \\
\hline H. Wallon & $\begin{array}{l}\text { La conciencia y la vida subconsciente. En G. Dumas } \\
\text { (Ed.), Nuevo tratado de Psicología (Vol 7I, fasc.1) }\end{array}$ & 1948 [1942] & Kapeluz \\
\hline H. Wallon & Del acto al pensamiento (2a. ed.) & $1964[1948]$ & Lautaro \\
\hline H. Wallon & Fundamentos dialécticos de la psicología & 1965 [1931-1956] & Proteo \\
\hline H. Wallon & Estudios sobre psicología genética de la personalidad & 1965 [1946-1962] & Lautaro \\
\hline H. Wallon & La evolución psicológica del niño & 1965 [1941] & Psique \\
\hline H. Wallon & Los orígenes del carácter en el niño & 1964 [1934]; 1965 & Lautaro \\
\hline H. Wallon & $\begin{array}{l}\text { Los orígenes del pensamiento en el niño (Vols. 1-2, 3.a } \\
\text { ed.) }\end{array}$ & 1965 [1963] & Lautaro \\
\hline $\begin{array}{l}\text { H. Wallon, J. Piaget y } \\
\text { otros }\end{array}$ & Los estadios en la psicología en el niño & 1963 [1956]; 1965 & Lautaro \\
\hline $\begin{array}{l}\text { S. Rubinstein, H. Wa- } \\
\text { llon, J. F. Le Ny }\end{array}$ & Problemas de teoría psicológica & 1965 [1955-1962] & Proteo \\
\hline H. Wallon, L. Lurçat & $\begin{array}{l}\text { El dibujo del personaje por el niño. Sus etapas y cam- } \\
\text { bios }\end{array}$ & 1968 [1957-1960] & Proteo \\
\hline
\end{tabular}

* Entre corchetes se indican las ediciones originales francesas. En el caso de compilación de artículos, se indica el rango de años cubierto. Las reediciones se indican luego de un punto y coma.

Fuente: elaboración propia

do Wallon fue recuperado por figuras de izquierda críticas del dogmatismo comunista.

Luego de 1968, no hubo nuevas traducciones argentinas aunque las ya realizadas tuvieron varias reediciones durante la década siguiente, como muestra la tabla 2, algunas en la editorial Nueva Visión, sin vínculos con el PCA. Ello es un índice de que las obras de Wallon tuvieron una circulación considerable en las décadas de 1960 y 1970; de hecho, formaron parte de diversos programas de las carreras de psicología. Empero, estos datos no son suficientes para sopesar adecuadamente su incidencia en la psicología argentina, donde el psicoanálisis y Piaget eran, por mucho, las referencias teóricas más importantes.

Hacia mediados de la década de 1970, las novedades editoriales sobre Wallon dejaron de pasar por la Argentina debido, al menos, a las siguientes razones. La industria editorial argentina tuvo un marcado descenso de actividades durante década de 1970 tanto por el rápido deterioro general de la economía como por la censura política de la

TABLA 2

Reediciones argentinas posteriores a 1968

\begin{tabular}{llcc}
\hline \multicolumn{1}{c}{ Autor/es } & \multicolumn{1}{c}{ Título } & Año & Editorial \\
\hline H. Wallon, J. Piaget y otros. & Los estadios en la psicología en el niño & 1971 & Nueva Visión \\
H. Wallon & La evolución psicológica del niño & $1972 ; 1979$ & Psique \\
H. Wallon & Del acto al pensamiento (2.a ed.) & $1974 ; 1978$ & Psique \\
H. Wallon & Los orígenes del carácter en el niño & $1975 ; 1976$ & Nueva Visión; Psique \\
H. Wallon & Los orígenes del pensamiento en el niño (Vols. 1-2). & 1976 & Nueva Visión \\
\hline
\end{tabular}

Fuente: elaboración propia 
dictadura iniciada en 1976. En contraposición, la industria editorial española comenzó un sostenido crecimiento en los años finales del franquismo (Aguado, 2006). En ese proceso, Pablo del Río Pereda, un psicólogo miembro del Partido Comunista Español, inició una editorial propia por consejo de René Zazzo, con quien se formó en psicología del desarrollo. Ese emprendimiento se inició en 1976 con el libro de Zazzo Psicología y marxismo. La vida y obra de Henri Wallon, y posteriormente, una vez conformado el grupo Infancia y Aprendizaje, que reunía influyentes psicólogos y pedagogos españoles, se retomaron nuevas traducciones y reediciones de Wallon (Palacios, 1980). Por otro lado, las obras de Braslavsky y Merani tuvieron cierta circulación en Latinoamérica, especialmente las de este último, quien reivindicó permanentemente las ideas del francés e incluso publicó una compilación de sus textos (Merani, 1966). Respecto de Caparrós, hacia principios de los setenta, las referencias a Wallon en sus textos casi desaparecieron, debido a que adoptó otros enfoques teóricos y se alejó de las referencias comunistas al alinearse con el peronismo revolucionario (Caparrós \& Caparros, 1976). Por último, frente a la nueva dictadura, Itzigsohn y Caparrós se exiliaron, el primero en Israel, y el segundo en su España natal.

\section{Conclusiones}

Esta sintética indagación sobre los canales de divulgación hispanoparlante de la obra de Wallon muestra que sus principales impulsores en la Argentina pueden hallarse dentro de la cultura filosoviética y comunista. Ello se debió tanto al recorrido político del mismo Wallon, como a la red institucional conformada por los partidos comunistas en occidente y la figura del intelectual y científico comprometido erigida por el marxismo.

En la Argentina esta figura fue promovida por el movimiento antifascista, y luego por el comunismo, contra lo se consideraba un nuevo oscurantismo alimentado por un capitalismo fuera de control. $\mathrm{Da}$ da la expansión mundial del peligro fascista, dicho movimiento se fundó en la necesidad de establecer contactos entre diversos contextos. Los vínculos entre el antifascismo y la cultura comunista fueron estrechos, especialmente por sus horizontes internacionalistas, los cuales trascendieron los límites partidarios. Una perspectiva transnacional de la historia de la psicología permite poner de relieve los circuitos culturales y científicos generados por estas organizaciones. En estos circuitos se articularon diversas instancias: intercambios materiales de saberes, interacciones entre disciplinas, cruces y tensiones entre actividades científicas y políticas. Dichos circuitos se generaron con objetivos específicos constitutivos de los criterios de legitimación de los saberes en juego, sea la renovación y defensa de la cultura, la generación de nuevas pautas de educación y socialización, o bien la emancipación de los pueblos.

La organización de una cultura de izquierda en Latinoamérica generó vías de circulación, recepción y discusión de saberes psicológicos, los cuales requieren reconstrucciones históricas para dar cuenta de la lectura e incidencia de los distintos conocimientos y autores en las diversas coyunturas. Un análisis histórico de la obra de Wallon y sus lecturas resulta inseparable del filosovietismo, el antifascismo y el comunismo que constituyeron, desde mediados de la década de 1930, una densa trama internacional de intelectuales de izquierda por la que circularon ideas, técnicas, ediciones y autores. En este sentido, la conformación y dinámica los circuitos de transmisión de la obra de Wallon son inseparables de los conflictos y mutaciones de las organizaciones políticas involucradas.

Desde una perspectiva transnacional, la legitimidad, implantación y agotamiento de ciertos saberes no dependería solo de sus cualidades epistémicas, sino de las transformaciones de los circuitos que marcan a los saberes con una serie de referencias. De la legitimidad de esas referencias depende la circulación de ciertos conocimientos y el espacio que llaga a ocupar dentro y fuera de las disciplinas. En estos términos, la historia de la psicología también puede pensarse como la historia de la difusión de saberes mediante circuitos que articulan elementos heterogéneos, en este caso, partidos políticos, movimientos intelectuales, editoriales, universidades y clínicas privadas. 
Cada una de estas instancias requiere de estrategias de análisis propios que den cuenta tanto de sus especificidades y permitan sopesar el impacto de cierto saber.

El estudio de la acreditación y traducción de la obra de Wallon no puede ser considerado solo en términos nacionales, especialmente si se considera que Latinoamérica, además de una lengua, ha compartido diversos movimientos políticos. Los enfoques transnacionales permiten reubicar el papel de lo nacional, tanto en las ideas de los actores a indagar como en el marco de análisis del historiador. Ello permite repensar los términos en que puede hacerse productiva una historia comparada de la psicología en Latinoamérica (Kocka, 2003). De hecho, dada la diversidad de procesos involucrados y el monto de fuentes necesarias para lograr una reconstrucción adecuada de la conformación de circuitos de saberes, la historia transnacional requiere un esfuerzo colectivo entre historiadores de diversos escenarios. En este punto, este artículo se limitó a ofrecer ciertos elementos e indicaciones para tematizar un plano de análisis en pos de una indagación de mayor escala sobre los vasos comunicantes entre la producción, circulación y puesta en práctica de saberes psicológicos y las tramas intelectuales e institucionales de la cultura y la política de izquierda latinoamericana.

\section{Referencias}

Aguado, A. (2006). 1956-1975, la consolidación del mercado interno. En J. L. de Diego (Dir.), Editores y políticas editoriales en Argentina 1880-2000 (pp. 125-162). Buenos Aires: Fondo de Cultura Económica.

Bleger, J., Caparrós, A., Pichon-Rivière, E., \& Rozitchner, L. (1969). Ideología y psicología concreta. Cuadernos de Psicología Concreta, 1, 8-41.

Braslavsky, B. (1992). La querella de los métodos de enseñanza de la lectura. Buenos Aires: Kapelusz.

Braslavsky, B. (1996). Testimonios para la experiencia para enseñar. Buenos Aires: Secretaría de Cultura y Bienestar Universitario de la Facultad de Psicología, Universidad de Buenos Aires.
Buchbinder, P. (2005). Historia de las universidades argentinas. Buenos Aires: Sudamericana.

Caparrós, A. (1964). Henri Wallon, psicólogo militante. En H. Wallon, Del acto al pensamiento (2.a ed., pp. 7-23). Buenos Aires: Lautaro.

Caparrós, A., \& Caparrós, N. (1976). Psicología de la liberación. Madrid: Fundamentos.

Carroy, J., Ohayon, A., \& Plas, R. (2006). Histoire de la psychologie en France. XIX ${ }^{e}-X X^{e}$ siècles. París: La Découverte.

Celentano, A. (2006). Ideas e intelectuales en la formación de una red sudamericana antifascista. Literatura y Lingüística, 17, 195-218.

Dagfal, A. (2009). Entre París y Buenos Aires: la invención del psicólogo (1942-1966). Buenos Aires: Paidós.

García, L. N. (2012). La recepción de la psicología soviética en la Argentina: lecturas y apropiaciones en la psicología, psiquiatría y psicoanálisis (1936-1991). (Tesis doctoral). Facultad de Filosofía y Letras, Universidad de Buenos Aires, Buenos Aires, Argentina.

Gouarné, I. (2010). Philosoviétisme et rationalisme moderne. L'introduction du marxisme dans les sciences humaines en France (1920-1939). (Tesis doctoral). Faculté des Sciences Humaines, Université de Nantes, Nantes, Francia.

Heilbron, J., Guihot, N., \& Jeanpierre, L. (2008). Toward a transnational history of the human sciences. Journal of the History of the Behavioral Sciences, 44(2), 146-160. doi: 10.1002/jhbs.20302

Herman, E. (1995). The romance of American psychology. Political culture in the age of experts. Los Angeles, CA: University of California Press.

Iriye, A. (2004). Transnational history. Contemporary European History, 13(2), 211-222. doi: 10.1017/ S0960777304001675

Judt, T. (1994). Past imperfect. French intellectuals, 1944 1956. Berkeley, CA: University of California Press.

Kocka, J. (2003). Comparison and beyond. History and Theory, 42(1), 39-44.

Le Bianic, T. (2005). Les «ingénieurs des âmes». Savoirs académiques, professionnalisation et pratiques des psychologues du travail de l'entre deux guerres à nos jours. (Tesis doctoral). Université d'Aix-Marseille II, Provence, Francia. Recuperada de http://tel.archives-ouvertes.fr/docs/00/09/61/16/PDF/These le bianic 1_.pdf 
Martínez, Y. (1946). Noticia sobre Henri Wallon. En H. Wallon, Psicología aplicada (pp. 7-11). Buenos Aires: Futuro.

Massimi, M., \& Carmo Guedes, M. (Orgs.). (2004). História da psicologia no Brasil: novos estudos. Sao Pablo: EDUC-Cortez Editora.

Merani, A. (1957). Del niño al hombre social. Un análisis de psicobiología infantil. Buenos Aires: Nueva Visión.

Merani, A. (Comp.). (1966). Presencia de Henri Wallon. Caracas: Universidad Central de Venezuela.

Palacios, J. (Ed.). (1980). Henri Wallon. Psicología del niño (Vols. 1-2). Madrid: Pablo del Río.

Pasolini, R. (2008). Scribere in eos qui possunt proscribere. Consideraciones sobre intelectuales y prensa antifascista en Buenos Aires y París durante el período de entreguerras. Prismas, 12, 87-108.

Ponce, A. (1974). Henri Wallon y el congreso de Bruselas. En Obras completas (Vol. 3, pp. 107-110). Buenos Aires: Cartago.

Prado Acosta, L. (2013, octubre). Apuntes para un estudio transnacional de la cultura comunista. Trabajo presentado en las XIV Jornadas Interescuelas-De- partamentos de Historia. Universidad Nacional de Cuyo, Mendoza, Argentina.

Stern, L. (2007). Western intellectuals and the Soviet Union, 1920-1940. London: Routlegde.

Tortti, M. C. (2002). Debates y rupturas en los partidos comunista y socialista durante el frondizismo. Prismas, 6(6), 265-274.

Troise, E. (1938). Materialismo dialéctico. Buenos Aires: La Facultad.

Turchetti, S., Herran, N., \& Boudia, S. (2012). Introduction: Have we ever been 'transnational'? Towards a history of science across and beyond borders. The British Journal for the History of Science, 45(3), 319. 336. doi: 10.1017/S0007087412000349

Vezzetti, H. (1991). Freud en langue espagnole. Revue Internationale d'Histoire de la Psychanalyse, 4, 189-207.

Vezzetti, H. (1996). Aventuras de Freud en el país de los argentinos. Buenos Aires: Paidós.

Vezzetti, H. (2009). Sobre la violencia revolucionaria. Buenos Aires: Siglo XXI.

Wallon, H. (1965). Fundamentos dialécticos de la psicología. Buenos Aires: Proteo.

Weinberg, G. (1947). Advertencia. En H. Wallon, Del acto alpensamiento (pp. 7-8). Buenos Aires: Lautaro. 
